\title{
A moda e a morte: ciclos de tendências
}

Fashion and death: Trends Cycles

Flavia Jakemiu Araújo Bortolon 


\section{A moda e a morte: ciclos de tendências}

Fashion and death: Trends Cycles

Flavia Jakemiu Araújo Bortolon

\section{Resumo}

A moda é composta de ciclos de tendências subpostos, que buscam eliminar o passado em busca de um novo, o que a torna efêmera e ao mesmo tempo eterna. $\mathrm{O}$ presente estudo buscou analisar como se dá a relação desses ciclos de tendências no tempo, por meio de uma breve historiografia da moda, considerando os preceitos teóricos de Simmel, Crane e Caldas. Serão utilizados ainda conceitos propostos por Agamben, tais como: dispositivo, a fim de classificar o sistema da moda; contemporaneidade, para compreender a ação desse fator em relação ao tempo e profanação, para identificar a capacidade de manter-se na sociedade. Conclui-se que a moda, assim como a morte, renova a sociedade, destrói e cria o novo, como um sistema naturalizado artificialmente.

Palavras- chave: Moda. Profanação. Ciclo.

\begin{abstract}
Fashion is composed of cycles subpostos trends that seek to eliminate the past for a new one, which makes it ephemeral and eternal at the same time. This study investigates how is the relationship between these cycles of trends over time, through a brief history of fashion, considering the theoretical rules of Simmel, Crane and Caldas. They will still be used concepts proposed by Agamben, such as: device, in order to classify the system of the fashion; contemporaneidade, to understand the action of that factor in relation to the time and profanation, to identify the capacity to maintain in the society. It is ended that the fashion, as well as the death, renews the society, it destroys and it creates the new, as a system naturalized artificially
\end{abstract}

Keywords: Fashion.Profanation. Cycle. 


\section{INTRODUÇÃO}

A relação da moda com a morte ocorre em função da efemeridade imposta por esta, que recusa sempre o passado em busca de um constante novo, em um fluxo contínuo no qual é mais fácil atingir a morte à moda. Segundo Svendsen (2010, p. 27), Kant foi o primeiro filósofo a relacionar a $\operatorname{Moda}^{1}$ com a busca pela inovação, ao afirmar que "a novidade torna a moda sedutora", diferentemente dos demais que a associavam com a busca pela beleza ${ }^{2}$.

Stéphane Mallarmé seguiu a mesma linha de raciocínio de Kant. Mallarmé foi editor da revista de moda "La dernière mode", de setembro e dezembro de 1874 (Figura 1). Para ele, "a beleza na moda não deveria ser buscada na atração de algo eterno, e de maneira nenhuma em qualquer funcionalidade, mas na pura temporalidade" (SVENDSEN, 2010, p. 29), ou seja, a moda se alimenta do transitório e do imediato. Neste período, a moda já dava início ao seu desenvolvimento industrial. O vestir tornouse importante mecanismo para que se atingisse e imprimisse caraterísticas modernas, fascinando escritores.

Na revista, Mallarmé trazia regras de vestuário para adequar-se ao novo. A primeira tiragem ( 3 mil exemplares) foi patrocinada pelo próprio poeta e contava com a ilustração em estilo gótico de Edmond Morin. Stéphane Mallarmé escreveu a maioria das matérias com pseudônimos, como "Marguerite de Ponty" (Moda e teoria da moda) e "Miss Satin" (dando notícias das modas de Paris).

\footnotetext{
${ }^{1}$ A moda enquanto Sistema - com letra maiúscula - que rege os ciclos do vestuário, mobiliário, costumes, etc., agora mais rápidos e constantes surge da segunda metade do século XIV, na Europa Ocidental. Diferença essencial que marca sua instauração: as mudanças não são aleatórias, agora são regra. São parte do funcionamento social (MESQUITA, 2007, p. 23).

${ }^{2}$ Como, por exemplo, o poeta Charles Baudelaire, que relacionava a moda com a busca pela beleza e a possibilidade de enganar as imperfeiçoes da natureza e do tempo com seus artifícios.
} 
FIGURA 1 - LA DERNIÈRE MODE

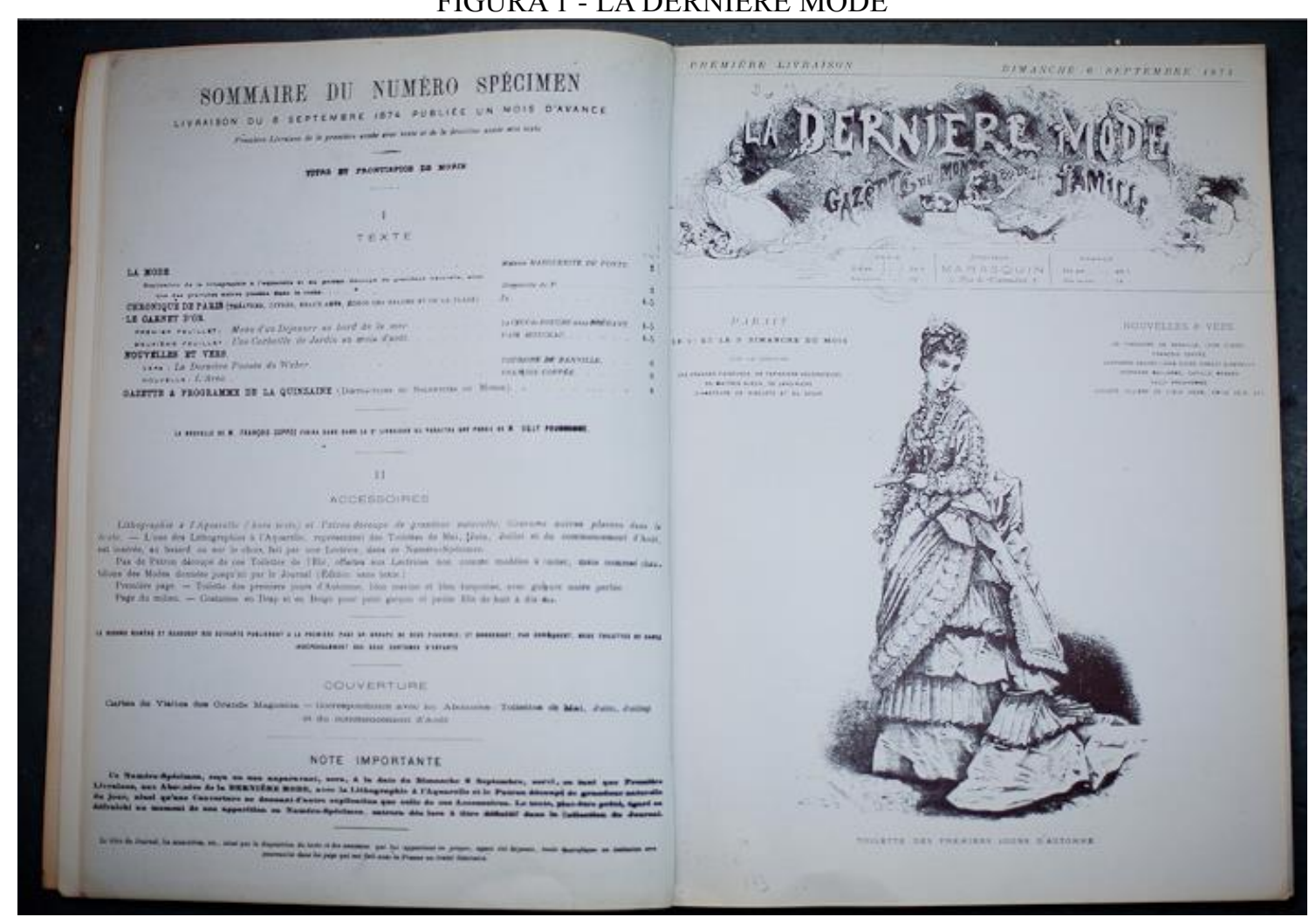

Nota: Edição original de 'La Dernière Mode', de 6 setembro de 1874.

Fonte: Site Vestoj (2016).

Conforme o exposto, pode-se verificar que, desde os primórdios, a moda presenteia a humanidade com seu caráter híbrido (efêmero e eterno). Nas próximas linhas, analisar-se-á como se dá a relação desses ciclos de tendências no tempo, baseando-se em uma breve historiografia da moda.

\section{REVISÃO DE LITERATURA}

Em 1824, o italiano Giacomo Leopardi $(1951)^{3}$ escreveu uma opereta, relatando um possível diálogo entre a Moda e a Morte. Giacomo começou a carreira com 10 anos de idade e desenvolveu suas atividades como poeta, tradutor e filólogo, vindo a falecer aos 39 anos $^{4}$.

A caraterística do novo exigido pelos ciclos da Moda a aproximava da renovação populacional da Morte. Na conversa, a Moda reivindicava a irmandade com a

\footnotetext{
${ }^{3}$ LEOPARDI, Giacomo. Dialogo della Moda e della Morte. In.: Operette Morali. Milano: Rizzoli Editore, 1951. p. 29-33.

${ }^{4}$ Leopardi nasceu em 29 de junho de 1798, na cidade Recanati (região central da Itália), e morreu, em Napoli, no dia 14 de junho de 1837.
} 
Morte. "Somos irmãs", afirmava a Moda, "ambas nascemos da Caducidade". A constante renovação estaria no cerne das duas, continua a Moda:

Digo que a nossa natureza e uso comum é de renovar continuamente o mundo, mas tu desde o princípio te lançaste sobre as pessoas e o sangue; eu me contento no máximo com as barbas, os cabelos, as roupas, os bens domésticos, os palácios e coisas afins. (LEOPARDI, 1951).

A moda estabelece modificações constantes nos hábitos para que se esteja adequado a ela. No diálogo ficcional, o poeta relata com ironia as exigências da Moda ao homem, as quais podem auxiliar na chegada precoce da Morte. Assim, de acordo com Leopardi (1951), a moda sujeita a pessoa a utilizar peças do vestuário com poucos tecidos e algumas que podem, inclusive, causar doenças, conforme trecho abaixo:

[...] persuado e constrinjo os homens nobres a suportarem todos os dias mil dificuldades e incômodos, e por vezes dores e sofrimentos, e outros, a morrer gloriosamente pelo amor que me têm. Não quero dizer nada das dores de cabeça, dos resfriados, dos refluxos de toda a sorte, das febres diárias, terçãs, quartãs, que os homens ganham por obedecer-me, consentindo em tremer de frio ou sufocar de calor, conforme eu queira, em proteger as costas com lãs e o peito com tecidos variados, e fazer tudo ao meu modo, ainda que seja em seu próprio detrimento.

O poder da Moda, de acordo com a análise do poeta, suplanta o das necessidades antigas e impõe novas regras de vivência, em que as aparências se tornam significativas para o homem. Na opereta de Leopardi (1951), a Moda ainda assevera o que se segue: "[...] impus ao mundo tais regras e tais costumes, que a própria vida, em relação ao corpo como à alma está mais morta do que viva".

É possível afirmar que a relação entre morte e moda está além das caraterísticas metafóricas da poesia, tanto é verdade que este século pode ser considerado o século da morte. A partir da década de 1820, ocorreram mudanças no vestuário masculino. A indumentária tornava-se mais funcional para a vida nas cidades, com modelagem mais simples, escurecida, predominando os tons de cinza e preto.

As mudanças de estilo ocorrem de maneira constante, conforme o tempo. Mas, qual é o tempo da moda? Como ela constrói o que é atual e o que deve ser descartado? Para exemplificar o descrito acima, pode-se usar a correlação que o teórico Giorgio Agamben (2009) estabelece entre a moda e a contemporaneidade. 
[...] o "agora" da moda, o instante em que começa a ser, não é identificável por nenhum cronômetro. Esse "agora" é o momento em que o estilista concebe o traço, o matiz que definirá a nova forma das peças? Ou no qual ele a confia ao desenhista e depois à costureira que confecciona o protótipo? Ou, melhor, o momento do desfile, onde a peça é levada pelas únicas pessoas que estão sempre e somente na moda, as manequins, que, no entanto, justamente por isso, nunca o estão realmente? Porque, em última instância, o estar na moda da "forma" ou da "maneira" dependerá do fato de que as pessoas de carne e osso, diferentes das manequins - vítimas sacrificiais de um deus sem rosto - a reconheçam como tal e a convertam em sua vestimenta. (AGAMBEN, 2009, p. 67).

De acordo com Agamben (2009), o tempo da moda está sempre adiantado a si mesmo e, por isso, também sempre atrasado; sempre tem a forma de um limiar inapreensível entre um 'ainda não' e um 'já não'. Assim, é impossível saber quando passamos do limite entre o pertencer e o excluir. Todavia, a relação da moda com o tempo ainda ocorre de mais uma forma, com a revisão de um passado notório, por exemplo.

\begin{abstract}
Mas a temporalidade da moda tem outro caráter, que a assemelha à contemporaneidade. No próprio gesto em que seu presente divide o tempo segundo um "já não" e um "ainda não", ela cria com esses "outros tempos" certamente com o passado e talvez também com o futuro - uma relação particular. Ela pode, vale dizer, "encontrar" e, dessa maneira, reatualizar qualquer momento do passado (os anos 20, os anos 70, mas também a moda império ou neoclássica). Pode, portanto, colocar em relação o que dividiu inexoravelmente, voltar a chamar, reevocar e revitalizar o que havia declarado como morto. (AGAMBEN, 2009, p. 68).
\end{abstract}

A moda traz consigo todas as questões com que nos encontramos para analisar os mecanismos do tempo - presente, passado e futuro. As tendências revisitam o passado para fazer delas novas criações. Nesta busca do novo, acabam presentificando o ontem. Exemplificando, a tendência de 20 anos retorna reformulada para as passarelas. A respeito dessa temática, Dario Caldas (2004) descreve:

Embora a moda desta virada de século seja marcada por uma relação constante com o passado, a tendência, como lhe é próprio, aponta sempre para o futuro. Mas o tempo da tendência é um horizonte de curto prazo. $\mathrm{O}$ que a mídia apresenta hoje como tendência estará nas vitrines das lojas e vestindo as pessoas em pouco tempo, e durará pouquíssimo tempo. Assim, a tendência projeta um futuro que também é permanentemente presentificado. No reino da obsolescência e da difusão instantâneas, a tendência não tem tempo de amadurecer e de transformar-se em moda, a tendência já é a própria moda. (CALDAS, 2004, p. 3). 
O ciclo da moda, gerado pelas tendências que se subpõem, acaba alimentando e aniquilando a própria moda. Como bem afirmado por Caldas (2004), a tendência torna-se a própria moda. Os dispositivos ${ }^{5}$ modernos se configuram de outra maneira (desejo, prazer, etc.), que, consequentemente, se traduzem nas relações de consumo. Na raiz de todo dispositivo está "um desejo demasiadamente humano de felicidade, e a captura e a subjetivação deste desejo, numa esfera separada, constituem a potência específica do dispositivo". (AGAMBEN, 2009, p. 44).

Assim como a morte, é impossível se desvencilhar da moda. Mesmo não fazendo parte do consumo de grifes, o sujeito faz parte deste dispositivo. Segundo Lipovetsky (2009, p. 266), “a moda é uma lógica social independente dos conteúdos; todas as condutas, todas as instituições são suscetíveis de ser levadas pelo espírito da moda, pelo fascínio do novo e a atração dos modernos". Nas palavras de Agamben (2009, p. 42), "hoje não haveria um só instante na vida dos indivíduos que não seja modelado, contaminado ou controlado por algum dispositivo".

Então, onde surgem e quem define os ciclos das tendências de moda? O primeiro a teorizar sobre o assunto foi Simmel, no início do século XX. Segundo este sociólogo, a moda resultava do desejo das elites em se diferenciar das classes médias e baixas e, dessas últimas de adquirir status por meio da adoção dos estilos dos grupos superiores.

A moda, com seu jogo entre a tendência para uma expansão universal e a
aniquilação do seu próprio sentido que comporta justamente essa expansão,
possui o atrativo singular do limite, o tratativo simultâneo do começo e do
fim, da novidade e, ao mesmo tempo, da caducidade. (SIMMEL, 2014, p.
16).

Logo, a disseminação da moda ocorria num ciclo sem fim, no qual uma substituía a outra por novas modas. Simmel tinha a visão de que a moda emanava de uma única fonte: as classes superiores e ia em direção as classes mais baixas.

\footnotetext{
5 Generalizando posteriormente a já bastante ampla classe dos dispositivos foucaultianos, chamarei literalmente de dispositivo qualquer coisa que tenha de algum modo a capacidade de capturar, orientar, determinar, interceptar, modelar, controlar e assegurar os gestos, as condutas, as opiniões e os seres viventes. [...] a caneta, a escritura, a literatura, a filosofia, a agricultura, o cigarro, a navegação, os computadores, os telefones celulares e - por que não - a própria linguagem, que talvez é o mais antigo dos dispositivos, em que há milhares e milhares de anos um primata - provavelmente sem se dar conta das consequências que se seguiriam - teve a inconsciência de se deixar capturar. (AGAMBEN, 2009, p. 40-41).
} 
Na década de 1960, esse processo unilateral de classes (superior para inferior), foi substituído pela moda do consumidor. Segundo Diana Crane (2011, p. 20), "em vez de se orientar pelos gostos das elites, a moda do consumidor incorporava gostos e preocupações dos grupos sociais, em todos os níveis de classe”. Como consequência, surge a difusão de novos estilos advindos das classes trabalhadoras. Em outros termos, estar na moda passou a se tornar um meio de expressar a identidade social.

No século XXI, ainda de acordo com Crane (2011), o sistema de moda ganhou um nível global, em que a palavra moda foi superada pela noção de tendências, ou seja, não há somente um único estilo para o consumidor seguir. A moda acaba por se tornar um agrupamento de tendências, no qual o consumidor faz escolhas não mais unicamente por determinação de estilistas, mas também por sugestão de especialistas da indústria da moda e de seu entorno. Essas tendências surgem de muitas fontes, desde culturas de rua, músicas, séries de TV, etc.

O fato de o ciclo da moda não ter um término possui uma relação de interdependência com a noção do profano, uma vez que a moda não somente se alimenta dos seus dispositivos, mas é capaz de restitui-los a um uso comum.

Em concordância com Agamben (2007, p. 66), profanar significa "abrir a possibilidade de uma forma especial de negligência, que ignora a separação, ou melhor, faz dela um uso particular". Portanto, no universo da moda, cada ciclo é retirado de seus princípios primeiros e profanado para um novo uso.

\section{METODOLOGIA}

Na tentativa de ilustrar o processo de ciclos de tendências de moda ao longo do tempo, bem como a sua relação com a conceituação de efemeridade, propõe-se a análise de dois objetos, isto é, duas fotografias (Figuras 2 e 3). Em uma, a subcultura punk levada para a passarela, nos dias atuais, enquanto que a outra apresenta a tendência do design de um produto, a bolsa ecológica. Segundo Peter Burke (2004), a fotografia possibilita conhecer um fato, podendo enriquecer um conhecimento, sendo usada como uma fonte, respeitando o contexto da época, meio social de produção e interesse "nas entrelinhas da imagem". Burke (2004) aponta ainda, que a imagem possibilita conhecer o vestuário de um período: 


\begin{abstract}
Alguns itens da vestimenta sobreviveram por milênios. No entanto, para mudarmos o foco do item isolado para o conjunto, para saber o que se usava com o que, é necessário recorrer a pinturas e gravuras, assim como a alguns manequins de moda remanescentes, principalmente do século XVIII ou de um pouco mais tarde. (BURKE, 2004, p. 99).
\end{abstract}

As imagens foram retiradas de sites, voltados para notícias de moda, o "Mondo Moda" pertence a jornalistas da cidade de Campinas, São Paulo, em 2007 e, segundo o editorial da página, está voltado para o público A e $\mathrm{B}$, entre 21 a 50 anos da cidade e região metropolitana de Campinas. O "My Fashion Life" é um site inglês, fundando em 2003, que traz guias de compras de tendências de moda. O editorial não traz um público específico, mas aponta grandes marcas e magazines (Lavin, Top Shop) como fontes de notícias. É importante apontar a origem das imagens selecionadas, pois, para Burke (2004, p. 225), “o significado das imagens depende do seu 'contexto social"". O contexto social, de acordo com o historiador, deve ser entendido como o lugar social de produção e circulação da imagem, no caso destas fotografias, os sites. Assim, nos sentidos obtidos pela imagem está inerente o contexto social de quem a produziu.

Para tanto, o conceito da subcultura escolhida deve partir dos estudos culturais britânicos de juventude e mídia propostos por Dick Hebdige, Ted Polhemus e Diana Crane. Com relação ao conceito de moda sustentável, serão utilizados os pressupostos de Donald Sawyer. Por fim, para auxiliar na compreensão de como a moda transforma um objeto de rebeldia ou preservação ambiental em produtos comerciais, o presente estudo receberá o subsídio teórico de Svendsen e Agamben.

\title{
RESULTADOS
}

Com o objetivo de exemplificar a ideia de moda como agrupamento de tendências, pode-se citar a subcultura punk. Dentro dos Estudos Culturais, o britânico Dick Hebdige foi um dos primeiros a analisar o desenvolvimento do punk, por meio da semiótica, baseado em Barthes e Eco, e do conceito antropológico de suposição de culturas. Segundo o autor, na década de 1970, o "Apocalipse estava no ar e a retórica do punk compreendia o apocalipse". Logo, os jovens britânicos e americanos daquela época buscavam novas estéticas, fato este que pode ser comprovado no trecho a seguir:

David Bowie e as bandas punks de Nova Iorque bandas tinham se reunido para formar uma variedade de fontes "artísticas" - a partir da avant-garde 
literária e cinema underground - uma estética conscientemente profana e terminal. Patti Smith, uma americana punk e ex-estudante de arte, afirmava ter inventado uma nova forma, "a poesia rock", e incorporou leituras de Rimbaud e William Burruoghs em suas apresentações. Bowie, também, citou Burroughs como influência e usou sua famosa técnica cut-up, de justaposições aleatórias, para "compor" letras. Richard Hell baseou-se em escritos de Lautremont e Huysmans. Bandas punks britânicas, geralmente mais jovens e mais autoconscientes do proletariado, permaneceram em grande parte inocente da literatura. No entanto, para melhor ou pior, as fontes literárias acabaram por ser firmemente inscritas, embora também o foram, implicitamente, na estética do punk britânico. (HEBDIGE, 1979, p. 27-28).

Dick Hebdige (1979), em "Subculture: the meaning of style", certifica que as subculturas são determinadas pela faixa etária e classe social e se expressam por intermédio da criação de estilos. Todo estilo é produzido conforme as conjunturas históricas e culturais específicas, sendo compreendido dentro de grupos. De acordo com Hebdige (1979), quando uma subcultura é assimilada mainstream, se tornando uma tendência, possibilitando sua exploração comercial, deixa de ser inovadora e passa a pertencer aos bens culturais, em que críticas são esvaziadas e se prima pela venda com foco na aparência.

Tão logo as inovações originais da subcultura são transformadas em mercadoria e colocadas à disposição, elas se tornam congeladas. Uma vez removidas dos seus próprios contextos por pequenos negociantes e grandes intérpretes que produzem moda numa escala de massa, elas são codificadas, assimiladas, tornadas, de uma vez por todas, propriedade pública e negócio lucrativo. (HEBDIGE, 1979, p. 84).

Sobre a simbologia incutida nas vestimentas dos integrantes do estilo punk, utilizaremos a descrição proposta por Diana Crane, relatada abaixo:

\begin{abstract}
Muito rapidamente, os elementos desse traje apareceram nas coleções criadas por estilistas de moda de luxo e em linhas de roupas de preços mais acessíveis. Em um processo totalmente diferente, o estilo punk, surgiu como expressão de niilismo extremo em uma pequena subcultura britânica, foi adotado mundialmente por adolescentes como meio de expressar sua angustia individual. Suas conotações sociais e políticas evaporaram; em vez disso, os elementos do estilo continuaram a ser um código de flutuação livre, largamente utilizado para expressar, através do vestuário, uma rebeldia totalmente dissociada das atividades e das crenças das contraculturas contemporâneas. (CRANE, 2006, p. 369).
\end{abstract}

O niilismo punk é revisado, profanado e passa a ser empregado sob um novo sentido, ou seja, a nova imagem passa a substituir o real. Segundo Agamben (2013, p. 73), utilizando-se da publicação de Guy Debord (A sociedade do espetáculo), 
o conteúdo perde lugar para a imagem, "e apresenta como uma imensa acumulação de imagens, em que tudo o que era diretamente vivido se tornou uma representação distante".

Na semana de alta-costura em Paris (mais especificamente, Primavera-Verão de 2011), o estilista Jean Paul Gaultier desfilou a coleção inspirada no punk-rock-inglês (Figura 2). Cada composição ganhou nomes, como "The Clash", "Belle Epoque", "Anarchy in the U.K.", inspirados em nomes de músicas punks. As modelos usavam moicanos coloridos, roupas com tachas e correntes, couro misturados com vestidos de seda e produtos artesanais. Para Svendsen, a rebeldia e os questionamentos da subcultura punk somente servem quando diluídas, haja visto que:

\footnotetext{
A individualidade só é significativa contra um pano de fundo de conformidade. A moda é sempre uma solução de compromisso entre duas coisas, como Simmel ressaltou há muito tempo. Se houver individualidade demais, ela perde seu apelo, porque deixa de funcionar de maneira distintiva, e está morta como moda. (SVENDSEN, 2010, p. 164).
} 
Figura 2 - Desfile Primavera - Verão de Jean Paul Gaultier em 2011

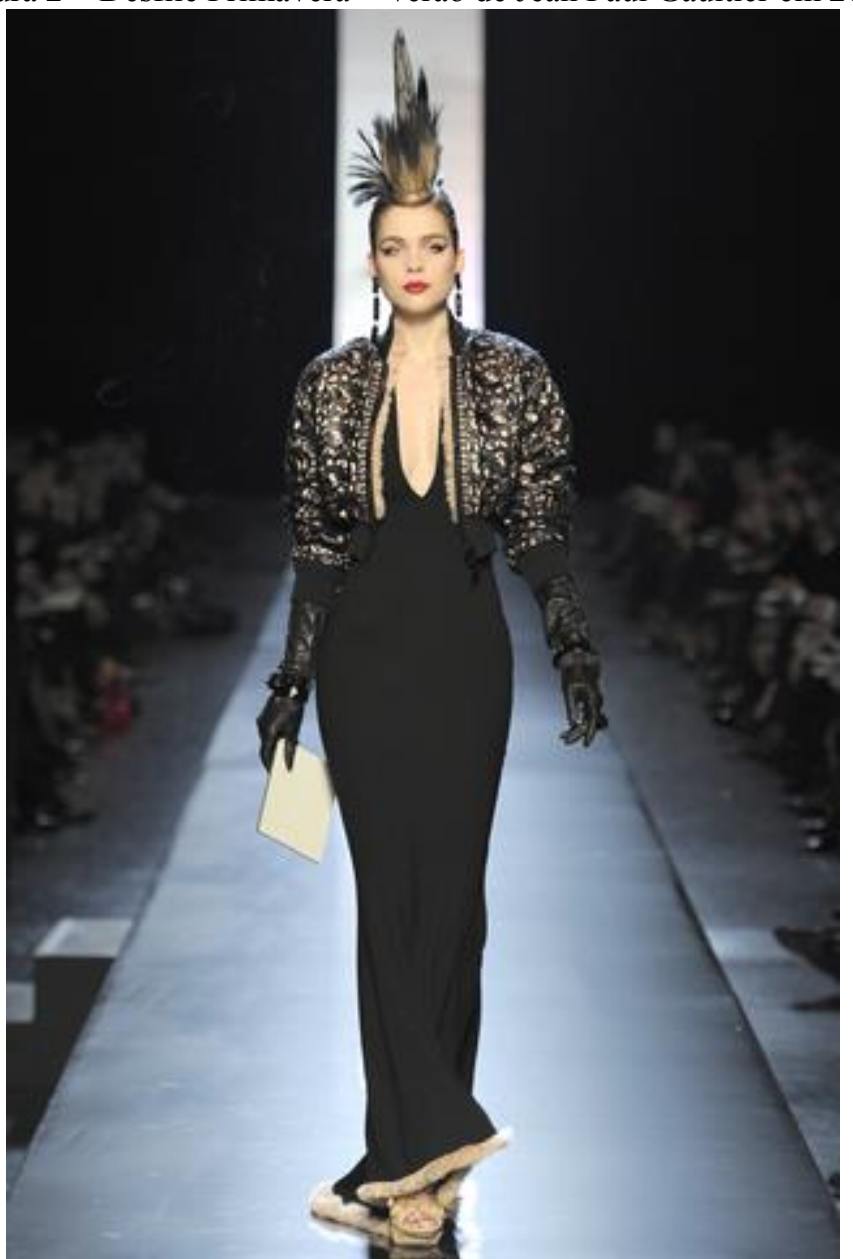

Nota: Desfile de Jean Paul Gaultier mistura elementos da alta costura com punk. Fonte: Site MondoModa (2016).

O site Mondo Moda, no qual retirou-se a fotografia do presente estudo, publicou uma seleção de outras 30 imagens do desfile ${ }^{6}$, todas trazem a modelo na ponta da passarela, onde costuma-se mostrar a composição completa do "look". A imagem foi selecionada por conceber os elementos do vestuário punk (jaqueta com tachas, a presença do couro) e um vestido com decote longo e profundo, geralmente utilizado em festas ou ocasiões especiais, o que provoca o contraste. A visualidade do vestuário, por meio das fotografias das matérias jornalísticas, permite confirmar o uso e criar uma nova percepção da realidade. Tal característica é comum em uma sociedade voltada para o consumo da moda e de elementos visuais, pois, segundo Svendsen (2010):

\footnotetext{
6 "Uma série de imagens oferece testemunho mais confiável do que imagens individuais". (BURKE, 2004, p. 237).
} 
A pluralidade no campo da moda é produto, em particular, de enorme quantidade de informações visuais que nos bombardeiam todos os dias. Susan Sontag afirmou que a sociedade se torna moderna quando uma de suas principais atividades é produzir e consumir imagens. Nesse caso, estamos perto de viver no mais moderno de todos os mundos possíveis. Todos nós nos tornamos, nas palavras de Sontag, "viciados em imagens". Segundo Hal Foster, somos incapazes de escapar da lógica da imagem, porque as imagens criam uma perda da realidade e, ao mesmo tempo, nos dão algo - isto é, novas imagens - que nos permite amenizar ou negar essa perda. As imagens se tornam um substituto para a realidade. (SVENDSEN, 2010, p. 165).

Todas as imagens publicadas nesta reportagem não possuem legendas, apenas são acompanhadas pelo texto que segue: “A referência punk estava nos cabelos com penas que formavam um cabelo Moicano, que se chocava com a quantidade de românticos plissados, franjas e babados". Conforme Burke (2004), as imagens não dão acesso ao mundo social diretamente, mas sim a visões contemporâneas daquele mundo, de quem a produziu e para quem, no caso, o site e o estilista em afirmar a produção da subcultura punk na passarela para fins do consumo de luxo.

Apesar do caráter transgressor respaldado e expressado pelo estilo punk, o consumo de roupas desse estilo foi amplamente aceito pela moda de massa. Esse episódio tratou do culto ao consumo de uma tendência, intercedido, há tempos, pela mídia impressa e narrado pelo teórico Svendsen (2010, p. 149), conforme excerto abaixo:

Já em 1977 - o ano em que o punk nasceu oficialmente, se bem que 1976 seria uma data mais precisa - o punk foi domesticado e tornado inofensivo por meio de artigos em jornais e revistas, cujo foco era como as roupas punk eram "bacanas". Isso significava na prática que elas já tinham sido assimiladas pela moda de massa.

Numa versão diluída, o vestuário punk foi incorporado na moda, na tentativa de imprimir características que permeiam o tom inovador, rebelde e jovem. $\mathrm{O}$ antropólogo Ted Polhemus (1996) expressa em seu livro "Style Surfing", que, na complexidade e fragmentação do mundo contemporâneo, haveria uma super valorização da aparência, e que a expressão de nossas personalidades e o reconhecimento de diferenças e similaridades, através da aparência, facilitariam a interação e o relacionamento entre as pessoas.

A moda se inspira nas subculturas e vem transformando seus códigos industrialmente, fazendo com que estes se tornem rapidamente comerciais. Este fenômeno joga no mercado produtos de origens e culturas esteticamente 
diversas e polifonias, formando assim, uma mistura de elementos de referências singulares. (POLHEMUS, 1996 apud MESQUITA, 2007, p. 95).

Em outras palavras, a moda utiliza-se de várias culturas (anteriormente foi a dos nobres, depois a das estrelas do cinema e ainda dos estilos advindos das ruas), com a intenção de reproduzi-las e revendê-las, destituindo-as de seu significado primeiro.

Outra forma de profanação do dispositivo, ou do sistema da moda, que ocorre atualmente é a proposta da moda com viés sustentável. Os ciclos de produção de novas tendências, que são mais recorrentes do que o modelo desejado ${ }^{7}$ com o fast fashion $^{8}$, deveriam ser subsistidos por ciclos longos, em que o consumo fosse o mínimo. Considerando este processo, outra corrente de consumo surge. Trata-se do chamado "verde"

O consumo verde, qual surgiu como movimento na década de 1980 (Harper \& Makatouni, 2002, p. 289), é em geral definido como "um conceito multifacetado que inclui: preservação do ambiente, minimização da poluição, uso responsável de recursos não renováveis e bem-estar animal e preservação de especiais [...] um processo de compra baseado em critérios ambientais e sociais". (McEachern \& McClean, 2002, p. 86). (CRANE, 2011, p. 243).

O que parece o fim da moda, pela eliminação do ciclo, é, na verdade, uma nova proposta de produto $^{10}$, o consumo eco-friendly, o slow-fashion ${ }^{11}$ e amigo da

7 A Zara possui um modelo de negócio que permite lançar no mercado cerca de dez mil novas peças por ano (H\&M, não cria por ano mais de dois mil a quatro mil itens, sendo que a maioria dos grandes retalhistas não ultrapassa as centenas), entregas nas lojas entre duas a seis vezes por semana, relatórios diários por parte das lojas (permite alterar constantemente as coleç̃es), lojas localizadas em locais de grande atração, pequenos lead times nos tempos de entrega, satisfação de ordens de encomendas em vinte e quatro a quarenta horas e entregas às lojas enviadas por avião, duas vezes por semana. (SILVA et al., 2011).

8 O fast fashion que troca grande parte das mercadorias das lojas a cada quinzena, contando com um planejamento da logística mundial e da criação acelerada de novos produtos.

${ }^{9}$ Os ambientalistas sustentam que é necessária uma mudança importante na natureza do consumo, no sentindo de que os produtos sejam produzidos de modo a proteger o ambiente e conservar os recursos, não de modo que a obsolescência dos bens de consumo seja o objetivo principal da produção e consumo dos produtos. (CRANE, 2011, p. 229).

10 É importante perceber que existem interesses econômicos por trás das novas propostas. De um lado, mudar o substantivo de desenvolvimento, com diversas dimensões (ao menos social e ambiental, se não outras) para "economia" pinça apenas uma das dimensões. Tende a empoderar os economistas e seus "instrumentos econômicos" no lugar de regulação estatal, que é taxada de "comando e controle". Natureza torna-se "capital natural". Essa abordagem teria um fundo corporativista profissional? De outro lado, muitos governos, empresários e organizações não governamentais estão buscando oportunidades de doação, negócios verdes e administração dos fundos a serem estabelecidos. Parece existir uma corrida atrás de green em espécie (moeda), o que suscita questões de conflito de interesse. (SAWYER, 2011, p. $3)$. 
natureza, alimenta uma nova forma de empreendimento econômico. Segundo Svendsen (2010, p. 160), "desprovidos de tradições, somos construtores hiperativos de estilos de vida, numa tentativa de formar significado e identidade", ou seja, isso se deve pela mudança na tentativa de autorrealização, com vistas para a formação da identidade, bem como para supri-la.

Em 2007, a estilista inglesa Anya Hindmarch criou um projeto, em companhia do movimento We Are What We Do (em tradução livre, Nós Somos O Que Nós Fazemos), que se tornou destaque entre os consumidores de moda. Tratava-se de uma sacola em tecido cru, com alças de corda, com a seguinte frase estampada num dos lados: "I'm not a plastic bag" (em tradução livre, Eu Não Sou Um Saco De Plástico) (Figura 3).

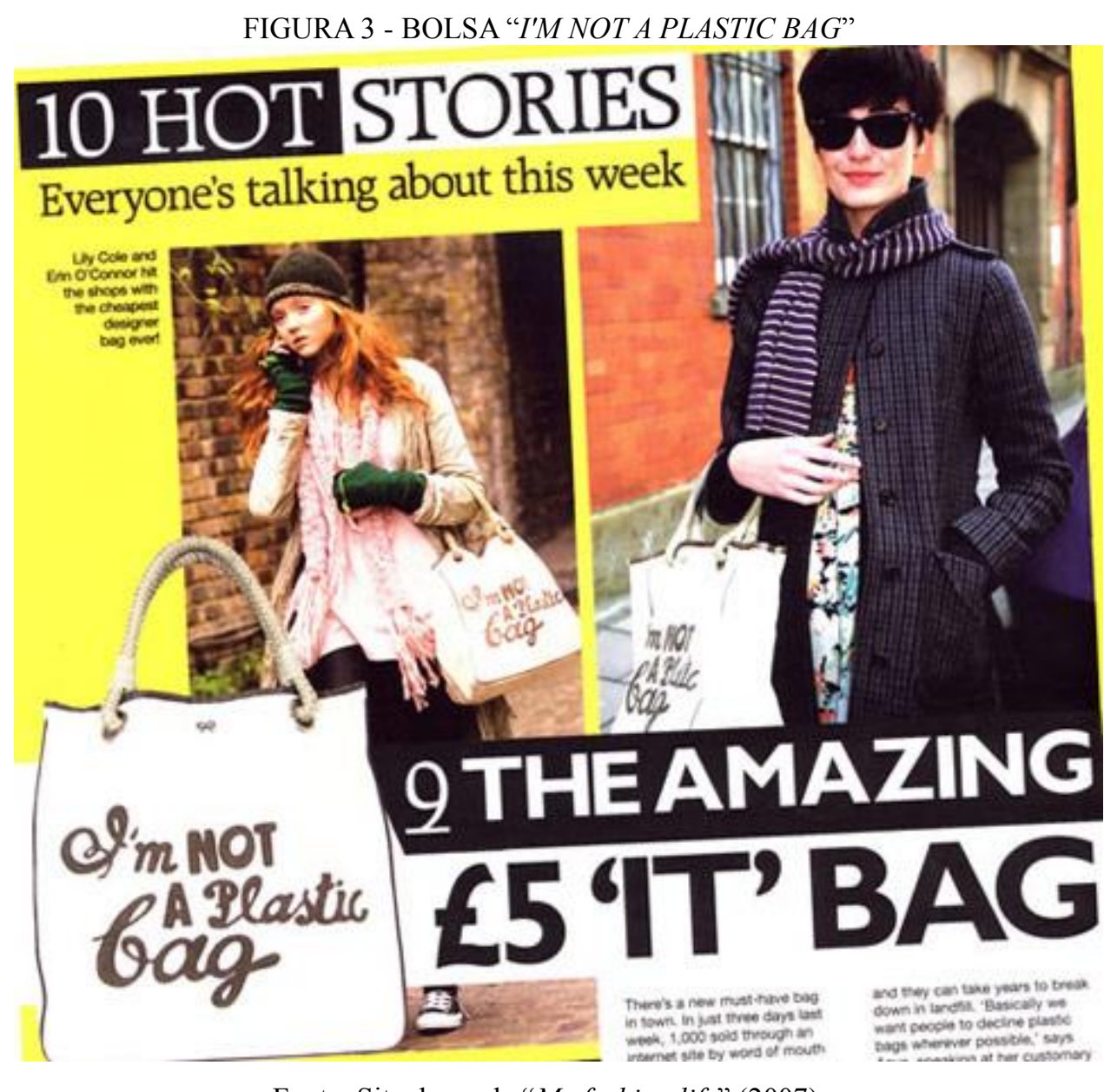

Fonte: Site de moda "My fashion life" (2007).

A bolsa vendeu 20 mil unidades em duas horas na rede Sainsbury's. O site contou com uma fila de espera de 100 mil pessoas interessadas no produto. A bolsa que,

11 A slow fashion promove a produção com menor impacto ambiental, o que não significa necessariamente baixar a produtividade, mas melhorá-la, pensando na qualidade do produto final, o que torna o processo amigo do meio ambiente (BLACK, 2008; LIVNI; SCUDER, 2016). 
inicialmente, custava 5 libras passou a ser revendida por 200 libras. O site "My Fashion Life", um guia de compras britânicas, apresenta a bolsa e os primeiros consumidores, artistas famosos e pessoas interessantes que estão falando sobre esta novidade. De acordo com Lipovetsky (2009), a importância das personalidades está ligada ao desejo de consumir a imagem que está sendo passada:

\begin{abstract}
A idolatria das estrelas não é de mesma essência que o religioso, não é senão uma das formas extremas da paixonite moderna. Diferentemente da adoração religiosa, inseparável de uma adoração simbólica, de um sentido ou de um conteúdo transcendente, a das estrelas tem de particular o fato que não se apega senão a uma imagem, é êxtase da aparência. Portanto, ao se defrontar, através da mídia, com imagens de estrelas utilizando a moda do filme, os consumidores sentem-se instigados a aderir também. (LIPOVESKY, 2009, p. 254).
\end{abstract}

A bolsa com proposta ecológica virou produto "fashion", exibido por celebridades da cultura pop, o que fez surgir várias outras bolsas inspiradas na mesma fórmula (bolsas para substituírem sacolas plásticas). No site que a imagem foi retirada, o texto da reportagem menciona que o uso por pessoas famosas, além de promover a divulgação da peça, ainda fez com que ganhe o produto ganhasse em valor financeiro: "De qualquer forma, com o endosso de celebridades, o resultado é que os sacos estavam custando £ 200 no eBay”. Apesar do furor envolvido quando da disponibilização da bolsa no mercado, a estilista Hindmarch foi acusada de não atender os princípios sustentáveis, pois a mesma era fabricada na China, país conhecido por exploração de mão de obra e por uso de materiais não orgânicos.

Em suma, o interesse do público consumidor ${ }^{12}$ não estava somente em não poluir o ambiente com sacolas não biodegradáveis, mas, sobretudo, estar adequado a moda. Para Svendsen (2010, p. 137), este desejo ocorre pela busca do reconhecimento e da identidade por meio de itens simbólicos.

Como Simmel enfatiza em sua filosofia da moda, esta sempre contêm dois elementos opostos, por um lado permitindo a indivíduos mostrarem-se como si próprios, mas, por outro lado, sempre mostrando-os como membros de um grupo. Um item de moda é, deste ponto de vista, ser um paradoxo ambulante, abraçando e expressando individualismo e conformidade ao mesmo tempo.

12 Outros estudos a respeito de consumidores verdes sugerem que os jovens podem entender a importância da moda ética, mas não tendem a concentrar suas compras nessa direção. O mercado da moda sustentável e ética pode consistir de mulheres mais velhas, que tendem a seguir menos tendências da moda. (CRANE, 2011, p. 241). 
A efemeridade dos produtos, combatida pelo interesse em preservação do ambiente com a redução de resíduos e gastos de meios para produção, não ocorre, quando o interesse do indivíduo é fazer parte justamente de uma nova tendência, no caso, a bolsa, para pertencer ao grupo eco-friendly e se destacar por escolhas aparentemente sustentáveis. Portanto, em consonância com Agamben, considerando a moda como um dispositivo, as tendências não correspondem a processos de subjetivação cujos resultados sejam sujeitos reais, mas tão somente espectros de sujeito.

\section{CONSIDERAÇÕES FINAIS}

A moda propicia um sistema efêmero e, ao mesmo tempo, eterno, quando gera uma sequência infinita de novidades, que são substituíveis por outras ad infinitum. O objeto permanece na moda somente até o instante em que o desejo ainda não foi realizado, pois, ao alcança-lo, este já foi substituído por um outro.

\footnotetext{
Através deste jogo entre a tendência para difusão geral e a aniquilação do seu sentido, que suscita justamente esta expansão, ela tem o peculiar fascínio das fronteiras, o fascínio do simultâneo começo e fim, o encanto da novidade e, ao mesmo tempo, o da efemeridade. A sua questão não é ser ou não ser; ela é ao mesmo tempo ser e não ser, encontra-se sempre na divisão de águas entre o passado e futuro e assim, enquanto persiste no seu clímax, dá-nos um sentimento muito forte de presença, como só poucos fenômenos o conseguem. Se no momentâneo auge de consciência social no ponto que ela caracteriza reside já o seu gérmen de morte, o seu destino para dissolução, ela não desclassifica totalmente este passado, mas acrescenta aos seus encantos outro novo. (SIMMEL, 2014, p. 34).
}

Simmel (2014) define a relação da moda com o tempo como o "ser" e o "não ser", o simultâneo "começo e o fim". O filósofo italiano Agamben descreve essa relação com um "já não" e um "ainda não". Ambos percebem como característica da moda esta definição de um tempo que transcorre, paradoxal e definível para o sujeito. Por outro lado, a ideia de moda também está relacionada com a morte. A moda é, para Simmel, o gérmen da morte e, para o poeta Leopardi, irmã da morte.

\footnotetext{
A noção de morte enquanto fim de um período e início de outro é intrínseca à própria moda, uma vez que todo seu funcionamento e seus ciclos baseiamse em rupturas - uma nova tendência busca sempre negar a anterior, formando um eterno ciclo de contratendências. Ao olhar o passado, de onde retira referências de formas e elementos decorativos, a indústria do fashion trabalha a reciclagem de propostas e aposta na "morte" para obter a ressurreição. (HOLZMEISTER, 2010, p. 100).
} 
Neste processo cíclico, aquilo que, até mesmo, poderia destruir o ciclo, acaba por ser reutilizado a seu favor. A ressurreição pode ocorrer pela releitura de uma antiga tendência, bem como pela profanação desta.

Se pensarmos no sistema da moda como uma relação de forças ou como um operador de transformações, podemos encará-lo como um dispositivo. Para Agamben, esta é uma estratégia possível na relação estrita entre nosso corpo e os dispositivos. Afinal, liberamos o que foi capturado e separado por meio dos dispositivos e restituímonos a um uso comum, seria o que o autor chama da "profanação".

O profano, no sentido de Trebazio, é aquilo que "de sagrado ou religioso que era, é restituído ao uso e à propriedade dos homens". Assim como a morte renova a população de tempos em tempos, também a moda renova e transforma os desejos. Quando não houver mais desejos, talvez este seja o fim dos estilos e das tendências de moda.

Artigo recebido em Agosto de 2016. Aprovado em Outubro de 2016 DOI:http://dx.doi.org/105965/1982615x10192016098

\section{REFERÊNCIAS}

AGAMBEN, Giorgio. Profanações. São Paulo: Boitempo, 2007.

AGAMBEN, Giorgio. O que é contemporâneo? E outros ensaios. Chapecó: Editora Argos, 2009.

AGAMBEN, Giorgio. A comunidade que vem. São Paulo: Boitempo, 2013.

BLACK, Sandy. Eco-chic: the fashion paradox. London, UK: Black Dog Publishing, 2008.

BURKE, Peter. Testemunha ocular: história e imagem. São Paulo: Edusc, 2004.

CALDAS, Dario. De trendsetters, modas e mídias: breve ensaio sobre a banalização do conceito de tendência na cultura contemporânea. In: COLÓQUIO BRASIL-FRANÇA DE CIÊNCIAS DA COMUNICAÇÃO E DA INFORMAÇÃO, 7., 2004, Porto Alegre. Anais... São Paulo: Intercom, 2004.

CRANE, Diana. A moda e seu papel social: classe, gênero e identidade das roupas. São Paulo: Editora Senac, 2006. 
CRANE, Diana. Ensaios sobre moda, arte e globalização cultural. São Paulo: Editora Senac, 2011.

HOLZMEISTER, Silvana. O estranho na Moda: imagem nos anos 1990. São Paulo: Estação Letras e Cores, 2010.

LEOPARDI, Giacomo. Diálogo della Moda e della Morte. In.: Operette Morali. Milano: Rizzoli Editore, 1951. p. 29-33.

LIPOVETSKY, Gilles. O Império do Efêmero: a moda e seu destino nas sociedades modernas. São Paulo: Companhia das Letras, 2009.

LIVNI, Ana; SCUDER, Fernando. Manifiesto MODA lenta SLOW fashion. Disponível em: <http://analivni.com/MODAlenta/filosofia.html>. Acesso em: 01 ago. 2016.

MESQUITA, Cristiane. Moda contemporânea: quatro ou cinco conexões possíveis. São Paulo: Editora Anhembi Morumbi, 2007.

OBI, Michele. I'm not a plastic bag!. 20 de março de 2007. Disponível em: $<$ http://www.myfashionlife.com/archives/2007/03/20/im-not-a-plastic-bag/>. Acesso em: 01 ago. 2016.

OLIVEIRA, Jorge Marcelo. Semanas de Moda - Primavera/Verão 2011 - Alta Costura - Jean Paul Gaultier. 27 de janeiro de 2011. Disponível em: $<$ https://mondomoda.com.br/2011/01/27/couture-spring-2011-gaultier/>. Acesso em: ago. 2016.

REDIGBE, Dick. Subculture and style. In: REDIGBE, Dick. The Meaning of Style. Methuen \& Co. Ltd, 1979. p. 1-4.

SAWYER, Donald. Economia Verde e/ou Desenvolvimento Sustentável?. Revista ECO21, v. 177, n. 8, p. 36-42, 2011. Disponível em: $<$ http://www.eco21.com.br/textos/textos.asp?ID=2507>. Acesso em: 01 ago. 2016.

SVENDSEN, Lars. Moda: uma filosofia. Rio de Janeiro: Zahar, 2010.

SILVA, Orlando Roque; VENANZI, Délvio; PAIXÃO, Marisa Regina. Estratégias de cadeias de suprimentos para o setor de vestuário-moda: uma análise das empresas Zara e H\&M. In: SIMPÓSIO DE ADMINISTRAÇÃO DA PRODUÇÃO, LOGÍSTICA E OPERAÇÕES INTERNACIONAIS, 14., 2011, São Paulo. Anais... São Paulo: FGVEAESP, 2011.

SIMMEL, George. A filosofia da Moda. Lisboa: Edições Texto e Grafia Ltda., 2014. 
THE AGED P. How sweet... BBC goes all nostalgic over the punks saying "Stuff The Jubilee" in 1977. Disponível em: <http://www.theagedp.com/?tag=punks $>$. Acesso em: 01 ago. 2016.

VESTOJ. Myth-making in the fashion magazine. Disponível em: $<$ http://vestoj.com/stephane-mallarmes-la-derniere-mode-and-myth-making-in-thefashion-magazine/>. Acesso em: 01 ago. 2016.

VILLAÇA, Nízia. Corpo à moda mídia na cidade do Rio de Janeiro. Projeto de pesquisa Construção do corpo na mídia: texto e imagem. Pós-Eco/UFRJ, 2008. 